\title{
TEMPORARY HIRES AND INNOVATIVE INVESTMENTS
}

MARCO MALGARINI

MASSIMO MANCINI

LIA PACELLI

Working paper No. 19 - March 2011 


\title{
Temporary hires and innovative investments
}

\author{
by Marco Malgarini*, Massimo Mancini and Lia Pacelli**
}

March 2011

\begin{abstract}
The flexicurity approach claims a positive effect of flexible labour on firm performance, also through an increased ability to innovate. Critics consider it a deregulation of the labour market, decreasing investment in human capital and innovation. We contribute to this broad debate providing an estimate of the relationships linking innovative investment, substitution investment, permanent hires and temporary hires. In particular, we aim at affirming or denying that innovative investments are accompanied by a specific kind of workforce, being it stable or flexible. In doing so, we contribute to bridge the gap among two quite separate strands of literature, as existing literature usually analyses capital and labour separately.

Estimating a non linear recursive equation system we highlight a significant increase in the likelihood of hiring on a permanent base when the firm innovates; this holds till 2008. Afterward, during the crisis, innovating firms are more likely to hire using temporary contracts instead, a possible signal of a cost saving strategy adopted in a loose labour market. Furthermore, both permanent and temporary hires never depend on increases in labour costs; however, substitution investment increases when labour cost increases, maybe in an attempt to increase labour productivity through a more efficient capital equipment.
\end{abstract}

Keywords: EPL, investment, innovation, flexicurity, survey data

JEL codes: J41, J6, D22, D24

* Istat, Piazza dell'Indipendenza 4, Roma 00185. The views expressed in the article are those of the authors and do not involve the responsibility of ISTAT.

** University of Torino and LABORatorio R. Revelli. Lia Pacelli gratefully acknowledges financing from Regione Piemonte, within the project ICT4LAW "per la convergenza fra tecnologie informatiche, diritto ed economia".

Corresponding author: Lia Pacelli, Department of Economics and Public Finance, c.so Unione Sovietica 218, Torino 10134. Tel +390116706038, fax +390116706062, elm: lia.pacelli@unito.it 


\section{Introduction}

In the last two decades, the European debate on economic growth and competitiveness on the global markets has been shaped by - among other things the so-called "flexicurity approach", i.e. by the aim to make European labour markets more flexible and at the same time to provide workers with a safety net against unemployment and human capital obsolescence. Supporters of flexicurity assert a positive effect of flexible labour $^{1}$ on firm performance; a better performance can be due to a decrease in labour cost as such or to an enhanced ability to innovate and increase productivity at the firm level. On the other hand, its critics emphasize the risk associated to a rise in temporary employment, that could decrease investment in human capital and hence innovation, performance and competitiveness in the longer run.

The link between hiring strategy and the ability to innovate products and/or production processes at the firm level is then crucial. However, existing literature usually analyses production factors separately, e.g. labour literature concentrates on the effect of temporary contracts on workers' career and on their productivity and training; investment literature focuses on lumpiness and aggregation issues or on investors' choice among innovative and non-innovative investment. In this sense, the interaction between different kinds of investment (more or less innovative) and different kinds of labour contracts (more or less flexible) at the firm level is often neglected, also due to the lack of suitable data.

The main innovation of this paper is that of contributing to bridge the gap between the two strands of literature, providing new insights into the degree of complementarity or substitutability at the firm level between different kinds of investment (that we label substitution and innovation) and different kinds of labour

1 The term flexible labour here is referred to the various forms of temporary contracts. 
hires (labelled temporary and permanent). We depict a sequential set of decisions on production factors the firm has to make every period, and we allow for observable and unobservable elements connecting them. In particular we identify the impact of having invested in innovative capital on the likelihood of hiring new workers with a permanent and/or with a temporary contract. Causal interpretation hinges on the specification of the model and on the ability to control for unobservables (section 5 discusses the point thoroughly). However, even a cautious interpretation of our results supplies important elements of reflection to the issue at stake. In fact, measuring if and to what extent capital innovation and labour flexibility are correlated - in a general sense - is crucial. It is the first but unavoidable step to understand whether the sharp turn toward labour market deregulation we have witnessed in Europe has been accompanied by an increased ability on the side of firms to compete on technologically advanced markets.

The focus of our paper is on the Italian manufacturing sector; Italy is indeed a case of special interest: in fact, Italian labour market institutions have dramatically changed since the nineties, with a sharp reduction of EPL for new hires ${ }^{2}$. Our main finding is the following. Fitting a non linear recursive equation system we estimate a significant increase in the likelihood of hiring on a permanent base when the firm innovates; this holds till 2008. Afterward, during the crisis, innovating firms are more likely to hire using temporary contracts instead. A possible explanation points to a cyclical element in this pattern, i.e. in upturns investment in physical and human capital go together, while in (sharp) downturns it emerges a cost saving strategy adopted by firms still able to innovate; strategy that is viable because the labour market is very loose, and in this sense it would represent an exception to the general rule matching innovative investment to a stable labour force. However, to be more definite on this statement we will need to wait for the development of this

\footnotetext{
${ }^{2}$ See for example Mancini (2007).
} 
pattern not only in the aftermath of the crisis that we are still experiencing (our last data point is very up to date, being December 2010) but also later on.

The paper is structured as follows: section 2 discusses the related literature, section 3 introduces the ISAE/ISTAT ${ }^{3}$ survey on manufacturing firms; section 4 provides descriptive evidence on hires and investments. The theoretical model we refer to, as well as the econometric approach are described in section 5. Results are discussed in section 6 . Some consideration on the results obtained will conclude the paper.

\section{Overview of the literature}

From a theoretical standpoint, the effects of the adoption of flexible labour contracts on firms' productivity are ambiguous. Large part of the economic literature in the '90s and early 2000s (see De Graaf-zijl, 2006 for a survey) states that flexibility allows firms to adapt more rapidly to fluctuations of demand, possibly increasing marginal efficiency and determining productivity gains via a reduction of labour hoarding. The human resource managerial literature challenged this vision (Hailey, 2001 for a survey), underlying that a high turnover of employees hinders the development of new ideas and hence of innovation. Storey et al (2002) add to this general statement documenting that employees are willing to provide discretionary effort and to accept the risk involved into innovative activity only if they feel secure in their employment relationship. Furthermore, they show that employees directly involved in innovative activity are "far less subject" to flexible employment contracts while if this is not the case the degree of innovativeness is lower; however, a flexible labour force employed in non-innovative activities can enhance the firm's innovative

\footnotetext{
${ }^{3}$ The Institute of Studies and Economic Analyses (ISAE) has been responsible for carrying out the survey until December, 2010. Starting from January 1, 2011, ISAE activities have been transferred to ISTAT, that is now in charge of the survey.
} 
performance. According to a more recent strand of economic literature, the use of flexible and temporary contracts may also reduce both the incentives for firms to invest in training and those for the workers to apply greater effort in order to acquire new skills; both consequences will have a negative effect on overall labour productivity and possibly also on TFP (e.g. Brandolini and Bugamelli, 2009). Moreover, according to Daveri and Parisi (2010), temporary contracts may negatively affect productivity also because the latter is positively related to experience, and flexible workers are on average less experienced than those holding an open ended job. MacLeod and Nakavachara (2007) show that when employment protection legislation becomes more stringent employment increases in occupations that imply high levels of skill and specific human capital investment; the opposite happens for low skill occupations.

A very recent spur of literature adds to this debate focussing directly on the link between flexible employment contracts and innovation at the firm level. Acharya et al (2010a)'s model shows that "stringent labour laws can provide firms a commitment device to not punish short-run failures and thereby spur their employees to pursue value-enhancing innovative activities". In Acharya et al (2010a), and also in a companion paper in which they apply a different empirical approach (Acharya et al, 2010b), they estimate that "innovation and economic growth are fostered by stringent laws governing dismissal of employees, especially in the more innovation-intensive sectors". A related work by Acharya et al (2010c) models the internal governance of firms, pointing to the positive effect of their long term commitment with subordinates in enhancing investment.

Albeit the relationship between flexibility and productivity is a highly debated issue, a positive effect of innovation on productivity growth is usually well documented by the data. Focussing on Italy, Parisi, Schiantarelli and Sembenelli (2006) find that the effect is particularly strong for process innovation; similarly, 
Pianta and Vaona (2007) show that the reduction in capital deepening occurred in Italy in the first decade of the new century, that has been associated with a reduction of R\&D and human capital expenditures, has contributed to explain the observed reduction in productivity. A similar effect of product innovation is found by Bugamelli, Schivardi and Zizza (2008), according to whom firms that are able to innovate their basket of products are also those experiencing higher growth of value added, profits and productivity. Similar results - based on a sample of firms extracted from ISAE archives - are found by De Nardis, Pappalardo and Vicarelli (2008). In this sense, the study of the relationship between labour market flexibility and innovation may ultimately help also to shed light on the more controversial issue concerning the relationship between flexibility and productivity growth. According to the existing empirical literature on Italy, the effect of labour market deregulation on firms' efficiency and (labour or total) productivity is not totally clear-cut. According to Cipollone and Guelfi (2006) the increase in flexibility has been very effective in reducing labour costs and hence stimulate employment growth. However, employment increases have been also associated with a reduction of both labour productivity and TFP (Lucidi, 2006) ${ }^{4}$. Similarly, Bassanetti, Dopke, Torrini and Zizza (2006) find that labour market reforms and wage moderation have favoured a process of substitution of capital with labour, inducing a slowdown in accumulation activity and limiting its support for growth. On the other hand, according to Boeri and Garibaldi (2007) the reduction in productivity associated with the adoption of more flexible labour market institutions should be considered as temporary; similar conclusions are reached by De Nardis (2007), according to whom new labour market institutions have favoured the adoption of more labour intensive production techniques, that in the short run may have had a negative effect on productivity, but

\footnotetext{
${ }^{4}$ This is consistent with Dew-Becker and Gordon (2008) on Europe as a whole and with Michie and Sheean (2003) for the UK.
} 
that may also result in an increase in firms' efficiency and productivity on longer time horizon.

We add to this literature focussing on a very recent period (up to December 2010), using the new and unique dataset of manufacturing firms described in section 3; we estimate directly the link between innovative investment and flexible contracts, and we also analyse how this link evolves over the current - and very special business cycle.

\section{The ISAE/ISTAT survey and the dataset}

The dataset used in this paper links firm characteristics to hiring and investment data and it is extracted from the ISAE/ISTAT survey on manufacturing firms. More specifically the survey provides monthly data about the current economic condition of the firm and its expectations; it also contains two special sections on investments and hiring decisions. The joint consideration of the monthly information and of the two special sections represents a unique source of data on capital, labour, production and demand at the firm level.

The ISAE/ISTAT survey is performed monthly as part of the Joint Harmonised Business and Consumers Survey (BCS) program of the European Commission ${ }^{5}$. The statistical unit considered for the survey is the firm. Referring to the Universe of all firms operating in the Class $C$ of the new NaceRev.2 Classification $(540,000$ firms), the BCS program targets firms with at least 10 employees (91,600 units). From this frame list a sample of 4,000 firms is extracted, hence representing $4.4 \%$ of the actual frame units. The sample is stratified along 3 axes, namely industry, macro-region and size of the firms; the method used for extracting the sample is the optimal allocation to strata, in which strata characterised by an higher internal variability are over-sampled with respect to those with a lower variability (Chiodini et

\footnotetext{
${ }^{5}$ http://ec.europa.eu/economy finance/db indicators/surveys/index en.htm
} 
al, 2009). The sample is treated as a panel, i.e. firms are re-interviewed each month, gradually substituting drop-offs with new firms extracted with similar criteria. The survey method is mixed, allowing for both telephone interviews supported by CATI system (80\%) and Fax interviews (20\%); emails are also used for a selected subsample of - mostly large - firms. The use of CATI and fax allows to reach a very high average response rate, that is currently around $95 \%$ of the target sample.

Business tendency surveys generally collect entrepreneurs' and managers' opinions on current trends and expectations for the near future, regarding both their own business and the general situation of the economy. Information is of a qualitative type, in the sense that respondents do not report quantitative data (e.g. the amount of production in one month), but qualitative, multiple-choice assessments on the behaviour of a variable (e.g. if production has increased, decreased or remained the same in a given month with respect to the previous one). Firms are asked to report about both the current situation of a given variable and their short-term forecasts on possible outcomes in the near future (usually three months ahead). In the case of the manufacturing survey, the monthly questionnaire includes qualitative information about current and expected level of production and demand, inventories of finished products, employment, liquidity constraints. On a quarterly basis, the survey alternatively adds questions about plant utilisation, working hours, export activity, and the firm' assessment about the competitive position of the firm. In the following we describe in more detail the two special sections on investment and hiring decisions.

\subsection{The investment section}

The investment section uses the same sample adopted for the general monthly survey. It is performed twice a year in the months of March and October (Cesaroni, Malgarini, Rocchetti, 2005). Survey method for this special section has changed 
during the years, with a considerable impact on average response rates: initially, it was performed via mail, and response rates were about $20 \%$ of the target sample of 4,000 firms. Since 2006, ISAE adopted a mixed mode technique, confirming the use of the mail mode for previously-responding firms and combining it with CATI and fax methods in order to obtain responses from "reluctant" units. Mixed mode resulted in an increase of the response rate to around $70 \%$ of the target sample. Starting from 2009, the survey has been entirely conducted with CATI and Fax methods, and as a result response rates increased to almost $95 \%$ of the target sample.

This questionnaire's section provides an estimate of the structure of investment expenditures and of their rate of growth; besides, it also provides qualitative information on the factors eventually influencing a revision of the investment plan during the year. It records investment in three consecutive years: investments of the two previous years and of the current one in the spring survey; investments of the previous, current and next year in the autumn survey. We make use of the October wave of the survey each year, and of the questions reporting investment on the same year.

As for the structure of investment, firms report about the share of expenditures respectively devoted to substitute for existing capital, rationalise the production process or increase the production, whether of new or existing products. For the purpose of the present work, we label as "substitution" investment those attributed by firms to substitution of existing capital or other reasons (e.g. security); we label "process innovation" all investments due to rationalization, i.e. those aimed at automation, or at introducing new production techniques, or at power saving; we also consider in this category all investments linked to environmental concerns and also investments coded as increase production of existing products. We finally label "product innovation" investments coded as increase production of new products. We 
then consider two non mutually exclusive subgroups: "substitution" and "all innovative".

From the survey it is possible to recover the monetary amount of each kind of investment, given the total amount recorded and the declared shares in each kind of investment. However, these questions are among the few questions comprised in the survey reporting quantitative measures, and as such may be particularly subject to non response biases and to measurement errors; in particular, shares of total investment show a clear heaping at round numbers. For these reasons, we choose to use only qualitative information on the kind of investment activity, considering whether or not the firm has realised substitution and/or innovative investments.

To give a flavour of the content of the survey, Table 1 shows the share of firms by kind of investment in the years of our analysis (2006-2010). Letting aside the expected decrease in investment when the crisis hits, the vast majority of investment is just a "substitution" of existing capital: 50\% of investing firms in 2006 perform only substitution investment; the percentage increases to $70 \%$ in 2010 after peaking to $80 \%$ in 2008 . The share of firms that either do not invest or just substitute existing capital increases from about $70 \%$ in 2006 to almost $90 \%$ in 2010 , so that different kinds of innovative investments involve about 30\% of firms in 2006 and just one out of ten firms in 2010.

The huge number of zeroes documented in table 1, i.e. no investment of any kind in the year, confirms the lumpy/inaction dynamics of capital, a fixed factor of production characterized by non convex adjustment costs (Caballero, 1999). In table 2 we confirm that there is not only inaction but also persistence in investment activity over time ${ }^{6}$. Firms that invested in the previous year are more likely to invest again in the current year, even though in 2010 the effect is much weakened with respect to 2006 (down from $80 \%$ to $60 \%$ of those who invested in year t-1 invest again in year

\footnotetext{
${ }^{6}$ For the sake of brevity, only two years are presented, reporting on two different points of the business cycle.
} 
t). The current investment is more likely to be aimed both at substitution and at innovation if the firm invested in the previous year. We will use this persistence as a control for firm general propensity to invest.

More descriptive evidence will be provided in section 4 .

\subsection{The labour market section}

Similarly to the investment section, also the labour market section (LMS) is performed on the same sample adopted for the general monthly survey on the manufacturing sector. It started in $2006^{7}$ and it is carried out once a year, initially in the month of December, and since 2009 in January (reference period being respectively the current and the previous year). It uses a mixed mode, CATI/Fax technique; hence, response rates are in line with those obtained with the standard monthly survey. Differently from the general business tendency survey, LMS provides several quantitative data. More specifically, it provides information about the number of people recruited along the year by the firm, and their distribution by type of contract. Contracts are distinguished by different levels of employment protection: open ended contracts, fixed term contracts, temporary agency work, trainees, and other types of contracts allowed in the Italian institutional setting (see ISAE, 2007, for a complete description of the survey). The questionnaire contains also information on skills of the new entrants (the percentage of hires with a degree or more) and on the recruitment channels preferred by firms: informal network, public employment services, private agencies (e.g. temporary help work), or other institutions (school, universities). Since 2008, firms provide also data on the end-ofyear stock of employees by type of contract. Finally, starting from 2009 , firms are also asked to report about the previous employment status of entrants, i.e. whether

\footnotetext{
${ }^{7}$ This is the reason why our period of analysis begins in 2006.
} 
workers come from unemployment, from another firm or from the same firm with a different contract.

Similarly to what has already been observed regarding the investment section of the survey, it should be considered that quantitative questions on hiring are among the few questions reporting quantitative measures that firms have to answer, and as such may be particularly subject to non response biases and measurement errors. For these reasons, we choose to use only qualitative information on hiring activity, considering whether or not the firm has hired using a given contract.

Section 4 will provide more descriptive evidence on the survey; here in Table 3 we consider whether the firm hires workers with different kinds of contracts. In general $80 \%$ (up to $90 \%$ in 2009 ) of those who hire do so using only one kind of contract: about $40 \%$ of firms use open ended contracts only, and another $30 \%$ uses fixed term contracts only; however for the first time in 2010 the share of firms hiring only with fixed term contracts overcomes the share of firms that hires only with open ended contracts. In 2006-2008 about $70 \%$ of firms did not hire workers, a percentage that jumps to $80 \%$ in $2009-2010$; as a consequence, also in this case a huge number of zeroes, i.e. no hiring of any kind in the year, occurs. This inaction classifies also labour as a factor of production characterized by non convex adjustment $\operatorname{costs}^{8}$.

On the basis of these information, correspondingly to the investment definition, we then consider two non mutually exclusive subgroups: "permanent" and "all temporary" hiring.

\footnotetext{
${ }^{8}$ Differently from the investment survey, in the labour market survey no retrospective questions about hires in the previous year are reported. This makes more difficult to check the persistence in hires, as matching two surveys at one year distance generates attrition problems in addition to those discussed in section 3.3.
} 


\subsection{The merged dataset and selection issues}

We start matching the 2896 firms in the November 2006 investment survey and the 3816 firms in the December 2006 labour market survey obtaining exactly 2700 matches (Table 4). This provides the endogenous variables on investment and hiring decisions. We then match the 2700 firms to their monthly questionnaires one year before, to obtain the exogenous determinants of the above decisions. After the match with the monthly questionnaires collected in December 2005 and in January 2006 (3726 observations) we are left with 2272 firms (78.5\% of the potential sample of 2896 firms). We then repeat the same for the following years, as reported in Table 4.

To check the absence of sample selection along observable characteristics of the firms we compare firms in the final sample and out of the final sample. Regarding the investment archive, mean and median firm size is unchanged in and out of the final sample, both within size classes, geographical areas, sectors, and overall. Conditional probability of being out of the final sample is marginally higher among small firms (under 15 employees) regardless of their investment decisions. Also regarding the labour market survey, mean and median firm size is unchanged, both within size classes, geographical areas, sectors and overall. Conditional probability of being out of the final sample is marginally higher among large firms (above 100 employees) regardless of their hiring decisions ${ }^{9}$.

Notice that even though the survey is built as a panel we use it as yearly cross sections, as attrition would decrease sample size significantly. In fact, despite the high response rate it is quite likely that firms skip one interview in the four we need each year to build the dataset (about 20\% every year, Table 4). Extending this over time would require responses to at least 8 interviews in two consecutive years and it would decrease the responding firms to a non representative subset (we would lose

\footnotetext{
${ }^{9}$ Results are available with the authors upon request.
} 
an additional $20 \%$ of firms every year, with a peak to $30 \%$ in 2009). This prevents the possibility of a dynamic specification of our model.

We weight all statistics and estimates using data from the official archive of existing firms (ASIA), referred to the year 2007; i.e. from ASIA we compute the distribution of firms by 4 geographical areas, 3 size classes (cut points 15 and 100 employees) and 15 manufacturing industries, and we weight our sample accordingly.

Having merged the two surveys we can consider hiring and investment decisions jointly. Table 5 presents a simple cross tabulation of kinds of investment and kinds of hiring at the firm level ${ }^{10}$. A large inaction does emerge; $32 \%$ of firms in 2006 and $47 \%$ of firms in 2010 neither invest nor hire. In both years firms not hiring are less likely to invest and even less likely to perform an innovative investment. On the other hand, those who do not invest are less likely to hire. In other words there are hints of a positive correlation between investment and hiring activity at the firm level.

\section{Descriptive evidence}

\subsection{Hiring and Investment}

In this section, we separately analyse the characteristics of the firms that hire (whether on a permanent or temporary basis) and invest (whether substituting existing capital or innovating). Section 6 will then be dedicated to the joint estimate of the two investment and two hiring decisions.

In the analysis, we consider a number of firm characteristics that we observe in the survey; this information is referred to the end of the year preceding hiring and investment decisions. More specifically, we use information regarding both the production process and the demand faced by the firm. The demand is approximated

\footnotetext{
${ }^{10}$ For the sake of brevity, only two years are presented, reporting on two different points of the business cycle.
} 
by the firm's assessment on the current level of orders, its competitive position and whether the firm exports a share of its production. To measure the level of production we consider the degree of plant utilisation (expressed in percentage of total capacity), the firm assessments on working hours, the existence of obstacles to increase production, liquidity constraints and the current level of production and inventories. Finally, we consider whether the cost of labour has increased according to the firm - above or below a 3\% threshold in the last 12 months.

Table 6 reports on the year $2006^{11}$. Firms making innovative investment are less likely to have reported a low level of demand the year before. They are also less likely to have faced obstacles to increase production, liquidity constraints, or a low production level. Non-investing firms, on the other hand, are less likely to have faced an increase in worked hours the year before. A past increase in the cost of labour is associated to substitution investment. Finally, the already noticed positive (unconditional) correlation between investment and hiring emerges again.

Turning now to analyse hires with the same approach (table 7 for the year $2006^{12}$ ) it emerges that firms reporting high demand levels are more likely to hire workers (both on temporary and permanent basis). The share of those reporting an increasing trend in working hours is generally higher for firms showing propensity to hire (both kinds of contract). Those having faced less obstacles in increasing the level of production are more likely to hire temporary workers. Again, the existence of a positive correlation between firms that show propensity to invest and those with a propensity to hire seems to be confirmed by the data.

Interestingly, Caggese and Cunat (2008) estimate that the existence of liquidity constraints should promote a more intense use of temporary contracts; in Table 7 this phenomenon does not seem to emerge, however the econometric model in section 6 will address the point more precisely.

\footnotetext{
${ }^{11}$ Statistics referred to the other years are not very different and are available upon request from the authors.
} 
In the next section, we set out a model aiming at disentangling confounding factors and actual relationships among the four factors of production considered. The descriptive evidence presented here provides a guideline in selecting the most relevant controls to be introduced in the econometric model.

Before doing so, we pause briefly to analyse promotions. Promotions are a source of increase in the number of permanent workers alongside permanent hires. They will not be included in the model, as they can be observed only since 2009 . However they are worth an in depth - although short - discussion, as the survey we use is a rare example of direct observation of this kind of decision alongside several other firm characteristics.

\subsection{Promotions}

Probit estimates of the probability of transforming temporary contracts into permanent ones, conditional on firm characteristics referred to the preceding year are shown in table 8 , with reference to the year 2009. Firms that transform a temporary contract into a permanent one are on average of a larger size; for a given size such probability increases when the competitive position improves and it decreases when average labour cost increases by more than $3 \%$.

Observing the same phenomenon from a different point of view, we can also consider the origin of individuals hired with a permanent contract by a given firm. Firms are asked to report whether all, some or none of the workers hired in the year were unemployed, were employed in a different firm with an open ended contract, and so on, as listed in Table 9. The most frequent origin is unemployment, followed by a job to job move from a permanent contract in a different firm; third, a promotion as above discussed. Other modalities are more and more unlikely.

\footnotetext{
${ }^{12}$ Statistics referred to the other years are not very different and are available upon request from the authors.
} 


\section{The model and the empirical strategy}

We aim at affirming or denying that innovative investments are accompanied by a specific kind of workforce, being it stable or flexible or - as Storey et al (2002) discuss - of both kinds (although employed in different occupations). We are also interested in estimating the effect of different firm characteristics on investment and hiring decisions.

The aim of this work is an empirical investigation; to solve a structural model goes beyond its scope. We will nevertheless refer loosely to a model that takes into account the joint dependence of (different kinds of) capital and labour adjustments toward an optimal level. We refer to a standard model of profit maximization subject to technology constraints and non convex costs arising when adjusting the level of inputs. Profits depend - ceteris paribus - on inputs' productivity, i.e. on the degree of innovation embedded in investments and on labour productivity linked to the contract used ${ }^{13}$. The dynamics of the model follows a so called $(S, s)$ rule, i.e. over time an exogenous costless negative drift decreases the level of the four inputs (not at the same rate), the drift respectively representing depreciation and technical/economic obsolescence for each kind of capital and quits or expiration of fixed term contracts for labour ${ }^{14}$. The negative drift affecting the production inputs decreases total output (Q) over time. When current output $Q$ is "too far away" from its desired level (call it $\mathrm{Q}^{*}$ ) the firm adjusts one or more inputs, hiring and/or investing. "Too far away" means that adjustment costs have become lower than lost profit due to the output gap $Q^{*}-\mathrm{Q}$. Hence, the probability of adjustment of each factor depends on $\mathrm{Q}^{\star}-\mathrm{Q}$ and on the size of its adjustment cost. Abel and Eberly (1998)

\footnotetext{
${ }^{13}$ E.g. permanent workers enjoy higher investment in firm specific human capital, as empirical analysis seems to confirm (de Graaf-Zijl, 2006).
} 
prove that the difference between the level of output that triggers adjustment (Q') and the target level of output $\left(Q^{*}\right)$ is an increasing function of the amount of adjustment costs. This setup holds exactly when modelling the dynamics of a single production factor (see Caballero, 1999). Abel and Eberly (1998) model a two-factor production function with fixed adjustment costs on one factor only. They show that "when factors of production can be adjusted at no cost, the mix of factors can be considered separately from their scale. When investment is irreversible and subject to a fixed cost, the quasi-fixity of capital eliminates the dichotomy between factor mix and scale and it can give rise to labour hoarding, even when labour is a purely flexible factor". In other words, adjustment costs generate an "optimal" correlation between the adjustment decisions of all factors of production. Extending their result to our four-factor framework - and approximating a formal solution that goes beyond the scope of the present work - we consider that the size of adjustment costs of each factor generates the sequence of decisions embedded in our recursive model. In Abel and Eberly (1998) capital is adjusted at longer intervals, while - conditional on investment decisions - labour is adjusted at a higher frequency. In our model we have innovative and substitution capital, permanent and temporary labour; we now turn to discuss the costs faced by the firm when modifying the level of each of the four inputs, and hence the sequence of adjustment decisions.

All production factors show inaction in our data, hence they all face non-convex adjustment costs. While the literature reports empirical evidence of small firing costs involving temporary contracts, and of substantial firing costs in adjusting the level of

\footnotetext{
${ }^{14}$ On top of the exogenous and costless negative drift there can be an endogenous/costly negative adjustment (firings) triggered by hitting the upper threshold of the $(\mathrm{S}, \mathrm{S})$ band. These lumpy events are unobservable to us, and are de facto included in the error term. To grasp their eventual impact we compare estimates referred to different phases of the business cycle, expecting layoffs to be more common during the crisis than in previous years.
} 
permanent employees in continental Europe ${ }^{15}$, little evidence exists on hiring costs. However, Pacelli (2001) provides evidence also on hiring costs referred to Italian firms, confirming the high cost of searching and training permanent employees, a cost that does not emerge for temporary ones. On the basis of the evidence of high adjustment costs referred to permanent labour contracts, we impose the following sequence of decisions, where permanent hiring precedes substitution investment:

— innovative capital: highest adjustment costs, e.g. due to R\&D, patents, search for the appropriate equipment;

- permanent labour: high adjustment costs, e.g. due to search, training, investment in human capital;

— substitution capital: low adjustment costs, e.g. due to production disruption when installed;

— temporary labour: lowest adjustment costs, e.g. due to (little) search and training.

Interactions among the different decisions are captured by including sequentially the decisions on the more "rigid" production factors into the equations estimating the decisions about the more flexible ones; in other words, decisions on innovative investment will not depend on the adjustment of other production factors, whilst permanent hiring will also depend upon innovative investments; in turn, substitution investment will also depend on permanent hiring and finally temporary hiring, being the last decision to be made by the firm, will depend upon the decisions

\footnotetext{
${ }^{15}$ Goux, Maurin and Pauchet (2001) estimate - in a convex adjustment cost framework - substantial costs to adjust the level of permanent contract workers in France; on the contrary they cannot find significant costs involved in adjusting the number of temporary contract workers. Aguirregabiria et Alonso-Borrego (1999) - in a linear adjustment cost framework - estimate that firing costs are between one third and half of the gross annual wage of permanent workers in Spain. They impose that hiring is made only with temporary contracts and estimate that hiring costs are about $15 \%$ of the gross annual wage of temporary workers. Rota (2001) estimates a labour demand model with fixed and linear adjustment costs with Italian data; she finds that fixed costs are substantial, around $40 \%$ of annual wage costs, and linear costs are much less important (3.6\% of annual wage costs).
} 
that the firm has made on all the three more "rigid" production factors considered in the analysis. Hence we estimate the following interdependent equations ${ }^{16}$ :

$$
\begin{aligned}
& I_{\text {innov }}^{*}=X_{1} \beta_{1}+\varepsilon_{1} \\
& H_{\text {perm }}^{*}=X_{2} \beta_{2}+\alpha_{1} I_{\text {innov }}^{*}+\varepsilon_{2} \\
& I_{\text {subst }}^{*}=X_{3} \beta_{3}+\alpha_{2} I_{\text {innov }}^{*}+\alpha_{3} H_{\text {perm }}^{*}+\varepsilon_{3} \\
& H_{\text {temp }}^{*}=X_{4} \beta_{4}+\alpha_{4} I_{\text {innov }}^{*}+\alpha_{5} H_{\text {perm }}^{*}+\alpha_{6} I_{\text {subst }}^{*}+\varepsilon_{4}
\end{aligned}
$$

and

$$
\begin{aligned}
& I_{\text {innov }}=1 \text { if } I_{\text {innov }}^{*}>0 ;=0 \text { otherwise } \\
& H_{\text {perm }}=1 \text { if } H_{\text {perm }}^{*}>0 ;=0 \text { otherwise } \\
& I_{\text {subst }}=1 \text { if } I_{\text {subst }}^{*}>0 ;=0 \text { otherwise } \\
& H_{\text {temp }}=1 \text { if } H_{\text {temp }}^{*}>0 ;=0 \text { otherwise }
\end{aligned}
$$

I.e. at the beginning of every year, at instant-one the firm decides on $I_{\text {innov }}$, at instant-two on $H_{\text {perm }}$, and so on; then production starts. As anticipated in section 3 , we use a yes/no kind of information on the adjustment of each input, as quantitative measures are particularly subject to non response biases and to measurement errors. The $\mathrm{X}$ matrixes include predetermined observable firm characteristics capturing the $Q^{*}-\mathrm{Q}$ gap at the end of year $t-1$, i.e. they include several measures of demand at the firm level and of the production process characteristics registered at the end of the year preceding the investment/hiring decisions. Hence, our non linear recursive equation system (estimated according to Roodman, 2009) estimates the impact of adjustment decisions of the more rigid production factors on the adjustment of less rigid ones (the $\alpha$ coefficients) as well as the impact of the covariates (the $\beta$ coefficients).

All the errors are assumed to be identically and independently jointly normally distributed with an unrestricted covariance matrix $\Sigma$, to be estimated. Off diagonal

\footnotetext{
16 The model is not dynamic, as no panel data can be used to estimate it due to high attrition, as discussed in section 3.3
} 
elements of $\Sigma$ measure the covariance $\left(\rho_{\mathrm{ij}}\right)$ among errors in different equations of the system and, when they are significantly different from zero, they signal endogeneity, i.e. they signal that unobserved firm-specific characteristics contribute to the decision on the adjustment of more than one input.

As long as unobservable firm effects are correlated to right-hand-side variables only through this channel, i.e. only inputs can be correlated to errors while predetermined $X$ are not, then our estimates can take adequate care of unobservables. However, the causal interpretation of the $\alpha$ coefficients hinges on the specification of the model and cannot be pushed too far, as there might be persistence in decisions and in firm characteristics that goes beyond our control. In any case in the worst scenario we can measure the conditional increase in the probability of a permanent hiring when the firm invests in innovative equipment; or the conditional increase in the probability of a temporary hiring when the firm invests in innovative equipment and hires permanent workers, and so on. The next section discusses the specification and the results.

\section{Results}

We estimate the non linear recursive equation system (1)-(2) discussed in the previous section. The controls included in the model are measures of demand, production and costs at the firm level. The empirical specification needs to be parsimonious, as the model is highly non linear and very demanding on data. Hence the controls included in the specification have to be a subset of those displayed in Table 6 and Table 7. On the other hand, the different measures available as proxies of the same element (e.g. demand) show a high degree of correlation, so we could safely chose a few of them to represent them all. Furthermore, in the specification of $I_{\text {innov }}$ equation we include the (log of the) amount of total investment per employee in $\mathrm{t}-1$ as a proxy of the firm's general propensity to invest. 
The results are presented in Table 10, separately for the five years from 2006 to 2010. Most importantly, it emerges a positive increase of permanent hires when innovative investment are performed; the increase is statistically significant in all years up to 2008 - when the crisis hits. Since 2008 we estimate a positive increase in temporary hires, instead, when innovative investments are in place. A possible explanation points to a cyclical element in this pattern: in upturns investments in physical and human capital go together, consistently with the human resources literature discussed in section 2. In (sharp) downturns it emerges a cost saving strategy adopted by firms that are still able to innovate (only about $12 \%$ of the total, as shown in Table 1), i.e. they hire but using a cheaper contract. This strategy is viable because firms may expect workers to be committed to the firm even if they are hired on a temporary base, being the labour market so loose and alternative job offers very rare. In this sense the current crisis is more likely to represent an exception to the rule linking innovative investment and a stable workforce dealing with them. However, to be more definite on this statement we will need to observe the development of this pattern -and of promotion rates - not only in the aftermath of the crisis (up to December 2010) but also later on.

Hires of permanent workers do not modify the probability to hire with temporary contracts, neither positively nor negatively. This seems coherent with the above statement, where firms seem to match innovative investment either with permanent hiring or with temporary ones, but not both ${ }^{17}$ and also with descriptive evidence pointing to firms hiring mostly with one kind of contract (Table 3). On the other hand, decisions to invest in substitution and innovative capital are constantly positively correlated. Finally, permanent hires trigger substitution investment, although not in the whole period considered.

\footnotetext{
${ }^{17}$ The only significant coefficient "alpha-5" in Table 10 (permanent hiring in the equation of flexible hiring) has a pvalue of 0.096 and it is referred to 2008, the "transition year" in which innovative investment are positively correlated to both kinds of hiring.
} 
Turning to the impact of controls on investment and hiring decisions, several interesting patterns emerge. The probability of making innovative investments is lower for non-exporting firms, that are usually smaller and facing a lower degree of competition on the product market. On the contrary it is higher for firms not facing liquidity constraints, i.e. for firms that can easily finance investment. Persistence of investment is confirmed by the positive impact of (the log of) euro invested per employees in the previous year on the probability of making innovative investment.

In turns, permanent hires depend on the level of demand, and increase when demand is high. They never depend on increases in labour costs, though. The existence of liquidity constraints should promote a more intense use of temporary contracts, according to Caggese and Cunat (2008). In fact we find that the presence of liquidity constraints decreases permanent hires. However, we find that it decreases temporary hires too, hinting to a more general difficulty in financing the expansion of the workforce, than to a change in the workforce mix.

Substitution investment increases when labour cost increases, maybe in an attempt to increase labour productivity through a more efficient capital equipment (however, the effect is significant only before the crisis). It is interesting to notice that the price of labour does not impact on hires of any kind. As anticipated above, flexible hiring is decreased by the existence of liquidity constraints; and it is triggered by inventories below normal, but only in 2006 .

Finally, there is mixed support for endogeneity, also due to the not very high precision of the estimates. Covariance coefficients $\left(\rho_{\mathrm{ij}}\right)$ are significant at $10 \%$ level when involving substitution investment; they are significant at $15 \%$ level when involving innovative investment, although in selected years only (see the Appendix). However, precision of estimates is a recurrent problem in this work, due to the high demand on data to identify the model and due to the mostly qualitative nature of the 
data themselves. In any case, exogeneity of input adjustment decisions can be safely rejected.

\section{Conclusions}

Existing literature usually analyses firms' decision on the use of production factors looking separately at the choice among temporary and permanent contracts and at innovative or substitution investment decisions. In this paper, we have tried to shed some light on possible complementarities between different kinds of investments (more or less innovative) and different kinds of labour contracts (more or less flexible) at the firm level. In doing so, we have exploited the informative content of two special sections of the ISAE/ISTAT survey on manufacturing firms, respectively concentrating on investment activity and hiring strategy. In particular, we have estimated a model in which decisions about the use of production factors (capital and labour) are taken sequentially, starting from the most "rigid" factors (innovative investments, permanent hiring) to the more flexible ones (substitution investments, temporary hiring); we allow for endogeneity of sequential decisions estimating a non linear recursive equation system.

To start with, innovative investments (the first choice to be made by the firms) result to be positively linked to the historical propensity of the firm to invest (captured by the investment/employment ratio), to its degree of openness to international markets (captured by his status as an exporting firm) and to more cyclical factors (financial constraints).

The hypothesis that decisions on the most "rigid" factors do complement each other is also confirmed by the data: the probability of permanent hiring is indeed higher for innovative firms; in turns, more innovative firms - that are also hiring on a permanent basis - are also more likely to make non-innovative (i.e., substitution) investments and to hire on a flexible basis. To sum up, the fact that the firm is 
"innovative" (in the sense of making innovative investments) results to have a pervasive positive influence both on his propensity to make substitution investments and to hire both on a flexible and permanent basis.

Finally, and perhaps most importantly, a cyclical pattern emerges: the positive correlation between innovative investment and permanent hiring is statistically significant up to 2008 , whilst innovative investments are positively and significantly correlated to temporary hiring since 2008 . A possible interpretation is that in upturns investment in physical and human capital go together, while in downturns it emerges a cost saving strategy adopted by firms still able to innovate, strategy that is viable because the labour market is very loose and hence workers are likely to be committed to the firm even if hired with a temporary contract. In this sense it will be important to measure whether the promotion rate will be affected by this pattern in the next years. In general, to be more definite on this statement we will need to wait for the development of this hiring pattern not only in the aftermath of the crisis that we are still experiencing (our last data point is very up to date, being December 2010) but also later on. 


\section{References}

Abel A.B., J.C. Eberly (1994), A unified model of investment under uncertainty, American Economic Review 84, 1369-1384.

Abel A.B., J.C. Eberly (1998), "The mix and scale of factors with irreversibility and fixed costs of investment," Carnegie-Rochester Conference Series on Public Policy, Elsevier, vol. 48(1), pages 101-135, June.

Acharya, V., R. Baghai and K. Subramanian (2010a), "Wrongful Discharge Laws and Innovation," working paper, New York University Stern School of Business. Acharya, V., R. Baghai and K. Subramanian (2010b), "Labour Laws and Innovation," Working paper, New York University Stern School of Business.

Acharya, V., S. Myers and R. G. Rajan (2010c) "The Internal Governance of Firms, " Journal of Finance, forthcoming.

Aguirregabiria V. and C. Alonso-Borrego (1999). 'Labour contracts and flexibility: evidence from a labour market reform in Spain', manuscript.

Bassanetti A., Dopke J., Torrini R., Zizza R. (2006), "Capital, labour and productivity: What role do they play in the potential GDP weakeness of France, Germany and Italy?", Deutsche Bundesbank, Discussion Paper, Series1: Economic Studies, n. 9

Boeri T. e P. Garibaldi (2007), Two Tier Reforms of Employment Protection. A Honeymoon Effect? Economic Journal, vol. 117, n. 521, pp. 357-85.

Brandolini A., M. Bugamelli (2009), Report on trends in the Italian productive system, Questioni di Economia e Finanza (Occasional Papers) 45, Bank of Italy, Economic Research Department.

Caballero R.J. (1999), Aggregate Investment, in: J. B. Taylor \& M. Woodford (ed.) Handbook of Macroeconomics, , chapter 12, pages 813-862, 1999.

Caggese A., Cunat V. (2008), "Financing Constraints and Fixed Term Employment Contracts", Economic Journal, vol. 118, issue 533, pages 2013-2046 
Cipollone P., Guelfi A. (2006), "The Value of Flexible Contracts: Evidence from an Italian Panel of Industrial Firms", Banca d'Italia, Temi di discussione, n. 583.

Costantini M., de Nardis S., Mancini M. (2007), "Modifiche istituzionali e trasformazioni strutturali nel mercato del lavoro italiano" in L'Italia nell'integrazione europea, Rapporto ISAE, march.

Daveri F., M.L. Parisi (2010), Experience, Innovation and Productivity: Empirical evidence from Ital's slow-down, paper presented at the Aix-en-Provence Conference on "Firms, Trade and Development" and at the OECD-CESifo conference "Regulation: Political Economy, Measurement and Effects on Performance", Munich, pp. 1-23

De Nardis S. (2007), Ristrutturazione industriale italiana nei primi anni 2000: occupazione, specializzazione, imprese, in ISAE, Trasformazioni dell'Industria Italiana, Quaderni di discussione, December, pp. 7-52

De Nardis S., C. Pappalardo e C. Vicarelli (2008), The Euro Adoption's Impact on Extensive and Intensive Margins of Trade: The Italian Case, ISAE Working Paper, n. 101.

De Graaf-zijl, M. (2006). Economic and social consequences of temporary employment (PhD thesis)

Del Boca A. and P. Rota (1998). 'How much does hiring and firing cost? Survey evidence from a sample of Italian firms', Labour vol. 12, pp. 427-449.

Dew Becker I. e R.J. Gordon (2008), The Role of Labor Market Changes in the Slowdown of European Productivity Growth, NBER Working Paper, n.13982.

Goux D.E. Maurin and M. Pauchet (2001), Fixed-Term Contracts and the Dynamics of Labour Demand, European Economic Review, 2001, vol. 45, no 3, p. 533552 
Hailey, V., 2001, "Breaking the mould? Innovation as a strategy for corporate renewal," The International Journal of Human Resource Management, 12(7), $1126-1140$

ISAE, (2006), L'inchiesta ISAE sulle assunzioni effettuate dalle imprese nel 2005 e le previsioni per il 2006, Nota Mensile n. 3, March

ISAE (2007), "L'inchiesta ISAE sulle assunzioni effettuate dalle imprese nel 2006 e le previsioni per il 2007, Nota Mensile, n. 2, February

ISAE (2008), II mercato del lavoro italiano nel 2007 tra risultati positivi e l'emergere di alcune criticità, Nota Mensile, n. 3, March

ISAE (2009), "Le assunzioni nel 2008 nel settore manifatturiero: tipologie contrattuali, contrattazione integrativa, skills", Nota Mensile n. 4, April

ISAE (2010), La domanda di lavoro in tempi di recessione: posti vacanti e assunzioni nel settore manifatturiero, Nota Mensile n. 4, April.

Lucidi F. (2006), Is There a Trade-Off between Labour Flexibility and Productivity Growth? Preliminary Evidence from Italian Firms, paper presentato al XXI Convegno Nazionale di Economia del Lavoro, 14-15 Settembre, Udine.

MacLeod, W., and V. Nakavachara, (2007), "Can Wrongful Discharge Law Enhance Employment?" The Economic Journal, 117, F218-F278.

Mancini M. (2007), “Regimi di protezione all'impiego ed effetti sul mercato del lavoro: l'evoluzione della flessibilità in Italia", I Temi dei Rapporti ISAE, June

Michie J. e M. Sheehan (2003), Labour Market Deregulation, 'Flexibility' and Innovation, Cambridge Journal of Economics, vol. 27, n. 1, pp. 123-43.

Pacelli L. (2001): "Fixed Term Contracts, Social Security Rebates and Labour Demand in Italy", Progetto MIUR "Occupazione e disoccupazione in Italia: misura ed analisi dei comportamenti", Working Paper n. 36, Padova, Dipartimento di Scienze Statistiche, Università di Padova. 
Parisi M.L., F. Schiantarelli e A. Sembenelli (2006), Productivity, Innovation and R\&D: Micro Evidence for Italy, European Economic Review, vol. 50, n. 8, pp. 2037-061.

Pianta M. e A. Vaona (2007), Innovation and Productivity in European Industries, Economics of Innovation and New Technology, vol. 16, n. 7, pp. 485-99

Roodman D. (2009), Estimating Fully Observed Recursive Mixed-Process Models with cmp, CGD Working Paper 168. Washington, D.C.: Center for Global Development.

Rota P. (2001). 'Dynamic Labour Demand with Lumpy and Kinked Adjustment Costs', Fondazione Eni Enrico Mattei, Nota di Lavoro no. 20

Storey J., Quintas P., Taylor P., Fowle W. (2002), "Flexible employment contracts and their implications for product and process innovation," The International Journal of Human Resource Management, 13(1), 1-18. 
Table 1 Investment by kind of expenditure, years 2006-2010

\begin{tabular}{|c|c|c|c|c|c|c|c|c|c|c|}
\hline YEAR & $\begin{array}{l}2006 \\
\% \text { all }\end{array}$ & $\begin{array}{l}2006 \\
\% \text { of I }\end{array}$ & $\begin{array}{l}2007 \\
\% \text { all }\end{array}$ & $\begin{array}{l}2007 \\
\% \text { of I }\end{array}$ & $\begin{array}{l}2008 \\
\% \text { all }\end{array}$ & $\begin{array}{l}2008 \\
\% \text { of I }\end{array}$ & $\begin{array}{l}2009 \\
\% \text { all }\end{array}$ & $\begin{array}{l}2009 \\
\% \text { of I }\end{array}$ & $\begin{array}{l}2010 \\
\% \text { all }\end{array}$ & $\begin{array}{l}2010 \\
\% \text { of I }\end{array}$ \\
\hline no Investment & 45.1 & & 50.3 & & 45.6 & & 56.3 & & 58.4 & \\
\hline substitution & 27.9 & 50.7 & 25.7 & 58.9 & 35.6 & 81.4 & 31.1 & 71.1 & 29.4 & 70.6 \\
\hline sub-total: no I + subst & 72.9 & & 76.1 & & 81.0 & & 87.4 & & 87.8 & \\
\hline substitution and process innovation & 12.7 & 23.1 & 8.5 & 19.5 & 5.4 & 12.3 & 3.8 & 8.8 & 3.3 & 8.0 \\
\hline process inno & 7.4 & 13.4 & 8.1 & 18.4 & 5.7 & 13.1 & 4.9 & 11.2 & 4.5 & 10.8 \\
\hline substitution and product innovation & 0.7 & 1.3 & 0.4 & 1.0 & 0.2 & 0.5 & 0.5 & 1.2 & 0.7 & 1.7 \\
\hline product innovation & 0.9 & 1.5 & 0.8 & 1.8 & 1.3 & 2.9 & 1.7 & 3.8 & 1.4 & 3.3 \\
\hline process and produc & 1.9 & 3.5 & 1.3 & 3.0 & 0.7 & 1.6 & 0.7 & 1.5 & 1.1 & 2.7 \\
\hline substitution, process and product inn. & 3.5 & 6.4 & 4.2 & 9.6 & 2.2 & 4.9 & 1.1 & 2.5 & 1.2 & 2.9 \\
\hline
\end{tabular}

Note. Column percentages.

"\% all": share of firms by kind of investment;

"\% of I": share of firms by kind of investment computed among investing firms only.

Weighted statistics.

Table 2 Investment at the firm level (2006 and 2010)

\begin{tabular}{|c|c|c|c|c|}
\hline \multirow[b]{3}{*}{ Investment in t } & \multicolumn{4}{|c|}{ investment in t-1 } \\
\hline & \multicolumn{2}{|c|}{2006} & \multicolumn{2}{|c|}{2010} \\
\hline & No & Yes & No & Yes \\
\hline No & 73.5 & 19.7 & 78.4 & 40.8 \\
\hline Yes & 26.5 & 80.3 & 21.6 & 59.2 \\
\hline Substitution & 54.2 & 48.3 & 76.9 & 68.2 \\
\hline Innovative & 26.0 & 16.4 & 14.5 & 17.6 \\
\hline Both & 19.8 & 35.4 & 8.6 & 14.3 \\
\hline
\end{tabular}

Note: column percentages.

Weighted statistics. 
Table 3 Hiring by type of contract

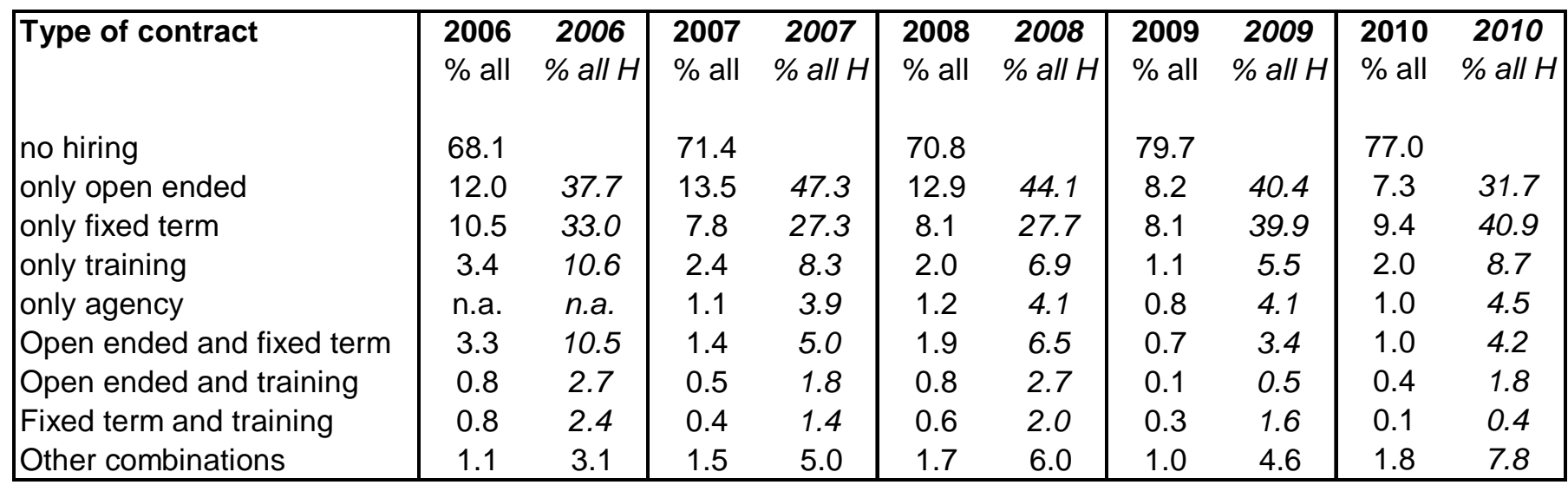

Note. Column percentages

"\% all": share of firms by kind of hiring contract;

"\% of H": share of firms by kind of hiring contract computed among hiring firms only.

Weighted statistics.

Table 4: sample size after the merge

\begin{tabular}{|l|c|c|c|c|c|}
\hline dataset lyear & $\mathbf{2 0 0 6}$ & $\mathbf{2 0 0 7}$ & $\mathbf{2 0 0 8}$ & $\mathbf{2 0 0 9}$ & $\mathbf{2 0 1 0}$ \\
\hline & & & & & \\
\hline investment (year t) & 2896 & 2918 & 3048 & 3829 & 3870 \\
\hline labour market (year t) & 3816 & 3701 & 3704 & 3816 & 3887 \\
\hline investment + labour market & 2700 & 2473 & 2810 & 3661 & 3616 \\
\hline monthly survey (year t-1) & 3726 & 3707 & 3572 & 3591 & 3825 \\
\hline & & & & & \\
\hline invest. + labour m. + monthly survey & 2272 & 2130 & 2434 & 3187 & 3143 \\
\hline$\%$ potential sample & 78.5 & 73.0 & 79.9 & 83.2 & 81.2 \\
\hline
\end{tabular}

Note. Absolute number of firms. No weighting. 
Table 5 Hiring and investment at the firm level (2006 and 2010)

\begin{tabular}{|c|c|c|c|c|c|}
\hline \multirow{2}{*}{\begin{tabular}{|l}
2006 \\
Hiring
\end{tabular}} & \multicolumn{5}{|c|}{ Investment } \\
\hline & No investments & Substitution & \begin{tabular}{|l|} 
Innovative \\
\end{tabular} & Both & Total \\
\hline No Hiring & 32.3 & 18.9 & 6.8 & 9.5 & 67.5 \\
\hline Permanent & 5.1 & 4.7 & 1.7 & 3.2 & 14.8 \\
\hline Temporary & 4.9 & 3.5 & 1.6 & 2.9 & 12.9 \\
\hline Both & 1.4 & 1.0 & 0.6 & 1.9 & 4.8 \\
\hline Total & 43.7 & 28.1 & 10.7 & 17.5 & 100.0 \\
\hline 2010 & \multicolumn{5}{|c|}{ Investment } \\
\hline Hiring & No investments & Substitution & \begin{tabular}{|l|} 
Innovative \\
\end{tabular} & Both & Total \\
\hline No Hiring & 47.5 & 21.5 & 5.1 & 2.9 & 77.0 \\
\hline Permanent & 6.6 & 4.5 & 1.0 & 1.2 & 13.3 \\
\hline Temporary & 3.6 & 2.3 & 0.7 & 0.7 & 7.3 \\
\hline Both & 0.8 & 1.0 & 0.1 & 0.5 & 2.4 \\
\hline Total & 58.5 & 29.3 & 7.0 & 5.2 & 100.0 \\
\hline
\end{tabular}

Note. Percentages of firms in each cell. Weighted statistics. 
Table 6: Investment in year $\mathrm{t}$ and firm status in year t-1 - year 2006

\begin{tabular}{|c|c|c|c|c|c|c|}
\hline & \multicolumn{6}{|c|}{ investment } \\
\hline & & & no & subst & innov & both \\
\hline \multicolumn{7}{|l|}{ DEMAND } \\
\hline \multirow[t]{2}{*}{ competitive position } & up & share & 0.062 & 0.100 & 0.128 & 0.115 \\
\hline & down & share & 0.098 & 0.067 & 0.078 & 0.099 \\
\hline \multirow[t]{2}{*}{ demand } & high & share & 0.121 & 0.181 & 0.154 & 0.166 \\
\hline & low & share & 0.304 & 0.310 & 0.228 & 0.287 \\
\hline \multirow[t]{2}{*}{ export } & no & share & 0.725 & 0.674 & 0.641 & 0.552 \\
\hline & & & & & & \\
\hline \multicolumn{7}{|l|}{ PRODUCTION } \\
\hline plant utilization & & average $\%$ & 69.695 & 71.706 & 73.784 & 74.092 \\
\hline \multirow[t]{2}{*}{$\begin{array}{l}\text { worked hours } \\
\end{array}$} & up & share & 0.085 & 0.138 & 0.136 & 0.139 \\
\hline & down & share & 0.165 & 0.146 & 0.126 & 0.177 \\
\hline obstacles & yes & share & 0.463 & 0.490 & 0.386 & 0.472 \\
\hline \multirow[t]{2}{*}{ liquidity constraints } & yes & share & 0.147 & 0.167 & 0.100 & 0.132 \\
\hline & no & share & 0.234 & 0.291 & 0.365 & 0.348 \\
\hline production & Iow & share & 0.286 & 0.265 & 0.205 & 0.271 \\
\hline \multirow[t]{2}{*}{ inventories } & high & share & 0.095 & 0.082 & 0.156 & 0.142 \\
\hline & Iow & share & 0.089 & 0.107 & 0.114 & 0.103 \\
\hline & & & & & & \\
\hline \multicolumn{7}{|l|}{ COST } \\
\hline \multirow[t]{2}{*}{ CMeLup3 } & & share & 0.094 & 0.135 & 0.090 & 0.163 \\
\hline & \multicolumn{6}{|c|}{ FACTORS } \\
\hline H temp & & share & 0.151 & 0.203 & 0.223 & 0.294 \\
\hline H perm & & share & 0.146 & 0.163 & 0.210 & 0.278 \\
\hline $\mathrm{I} / \mathrm{L}$ & & mean (000) & 4.788 & 3.545 & 7.815 & 9.769 \\
\hline & & & & & & \\
\hline number of firms & & share & 0.434 & 0.282 & 0.107 & 0.178 \\
\hline
\end{tabular}

Note. Share of firms by kind of investment.

E.g. among non investing firms, $6.2 \%$ states to enjoy its own competitive position to go up.

Weighted statistics. 
Table 7: Hiring in year $t$ and firm status in year t-1 - year 2006

\begin{tabular}{|c|c|c|c|c|c|c|}
\hline & & & & hiring & & \\
\hline & & & no & temp & perm & both \\
\hline DEMAND & & & & & & \\
\hline competitive position & up & share & 0.072 & 0.141 & 0.127 & 0.067 \\
\hline & down & share & 0.094 & 0.051 & 0.108 & 0.054 \\
\hline demand & high & share & 0.146 & 0.121 & 0.182 & 0.196 \\
\hline & Iow & share & 0.306 & 0.257 & 0.302 & 0.230 \\
\hline export & no & share & 0.688 & 0.624 & 0.671 & 0.585 \\
\hline & & & & & & \\
\hline PRODUCTION & & & & & & \\
\hline plant utilization & & average $\%$ & 70.978 & 73.144 & 71.147 & 74.266 \\
\hline worked hours & up & share & 0.088 & 0.175 & 0.168 & 0.161 \\
\hline & down & share & 0.150 & 0.188 & 0.142 & 0.215 \\
\hline obstacles & yes & share & 0.479 & 0.359 & 0.510 & 0.456 \\
\hline liquidity constraints & yes & share & 0.154 & 0.107 & 0.163 & 0.088 \\
\hline & no & share & 0.269 & 0.326 & 0.286 & 0.362 \\
\hline production & low & share & 0.287 & 0.252 & 0.217 & 0.201 \\
\hline inventories & high & share & 0.091 & 0.133 & 0.144 & 0.122 \\
\hline & Iow & share & 0.083 & 0.140 & 0.126 & 0.122 \\
\hline & & & & & & \\
\hline COST & & & & & & \\
\hline CMeLup3 & & share & 0.108 & 0.152 & 0.116 & 0.135 \\
\hline & & & & & & \\
\hline FACTORS & & & & & & \\
\hline I inno & & share & 0.243 & 0.337 & 0.351 & 0.519 \\
\hline I sost & & share & 0.424 & 0.538 & 0.504 & 0.588 \\
\hline $\mathrm{I} / \mathrm{L}$ & & mean (000) & 5.102 & 4.945 & 8.187 & 8.334 \\
\hline number of firms & & share & 0.670 & 0.148 & 0.131 & 0.050 \\
\hline
\end{tabular}

Note. Share of firms by kind of hiring.

E.g. among non hiring firms, $7.2 \%$ states to enjoy its own competitive position to go up.

Weighted statistics. 
Table 8: Transformation of temporary contracts into permanent ones

\begin{tabular}{|lcrrr|}
\hline & dy/dx & Coef. & Std. Err. & P >z \\
& & & & \\
\hline In Employee & 0.075 & 0.246 & 0.067 & 0.000 \\
\hline Labour cost>3\% & -0.132 & -0.475 & 0.284 & 0.095 \\
\hline Competitive position_up & 0.265 & 0.737 & 0.387 & 0.057 \\
\hline C & 0.234 & -1.307 & 0.267 & 0.000 \\
\hline & & & & \\
Prob > chi2 & 0.0007 & & & \\
Log pseudolikelihood & -246.99575 & & & \\
\hline
\end{tabular}

Note. Probit estimates, year 2009. Controls referred to 2008

Weighted statistics.

Table 9 Origin of hires with fixed term contracts (2009)

\begin{tabular}{|l|c|}
\hline ORIGIN & average $\left(^{*}\right)$ \\
\hline From unemployment & \\
\hline From open ended contract & 1.97 \\
\hline Promotion of atypical or freelance & 2.37 \\
\hline First job & 2.52 \\
\hline From non-open ended contract & 2.56 \\
\hline From mobility lists & 2.69 \\
\hline From the same firm (agency workers) & 2.73 \\
\hline
\end{tabular}

Note. Weighted statistics.

${ }^{*}$ ) Average of answers:

$1=$ all hires have been from ....,

$2=$ some hires have been from ...,

$3=$ no hires have been from ...., 
Table 10: Hiring and Investments at the firm level, mixed-process regression

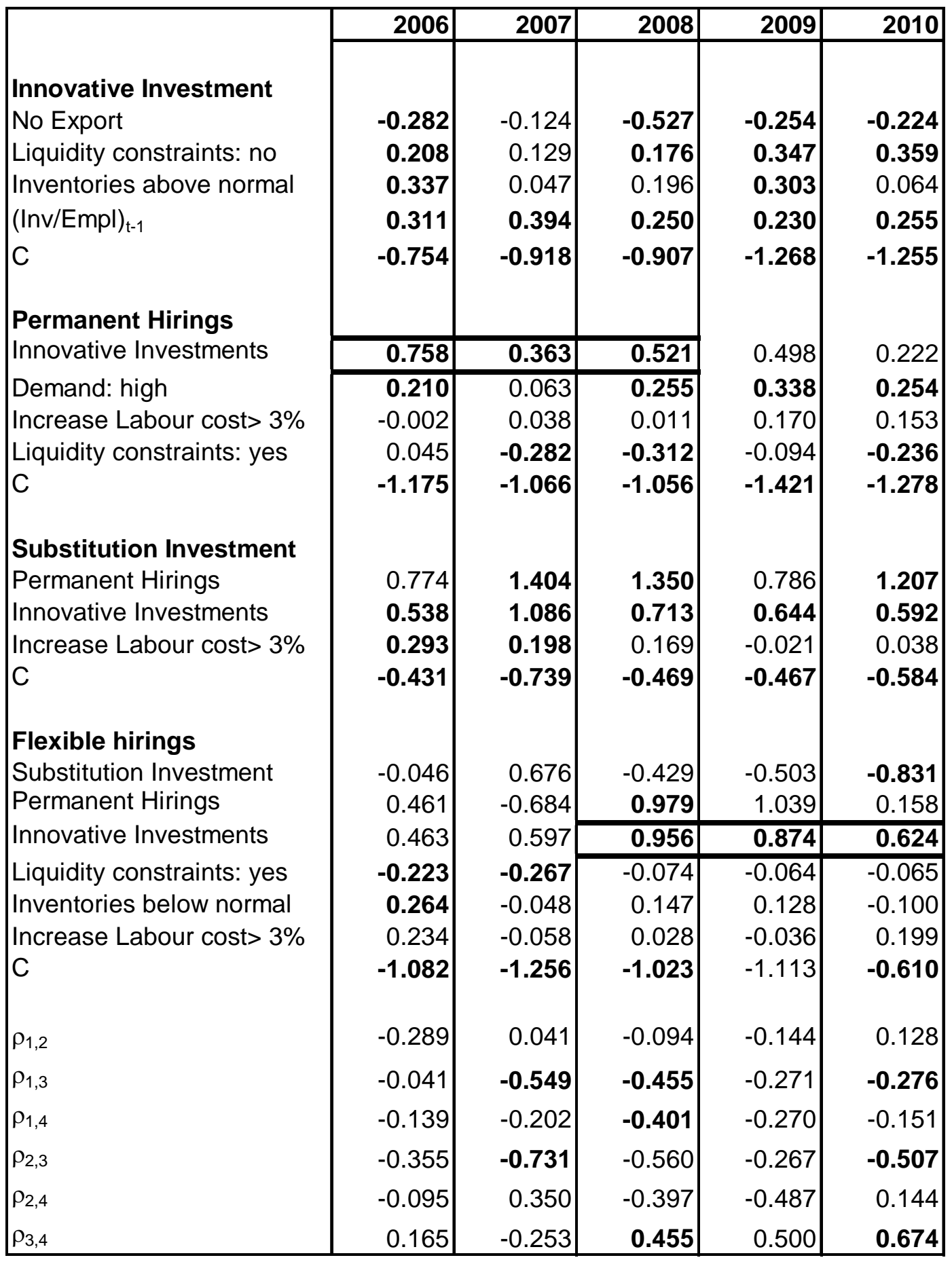

Note: in bold when significant at the $10 \%$ level. S.e. and diagnostics in the Appendix. 
Appendix : Complete estimated results

\begin{tabular}{|c|c|c|c|c|c|c|c|c|c|c|c|c|c|c|c|c|c|c|c|c|}
\hline \multirow[t]{2}{*}{ year } & \multicolumn{4}{|l|}{2006} & \multicolumn{4}{|l|}{2007} & \multicolumn{4}{|l|}{2008} & \multicolumn{4}{|l|}{2009} & \multicolumn{4}{|l|}{2010} \\
\hline & Coef. & Std. Err. & z & $P>z$ & Coef. & Std. Err. & z & $P>z$ & Coef. & Std. Err. & z & $P>z$ & Coef. & Std. Err. & z & $P>z$ & Coef. & Std. Err. & z & $P>Z$ \\
\hline \multicolumn{21}{|l|}{ Innovative Investment } \\
\hline No Export & -0.282 & 0.094 & -2.980 & 0.003 & -0.124 & 0.092 & -1.350 & 0.176 & -0.527 & 0.091 & -5.800 & 0.000 & -0.254 & 0.093 & -2.740 & 0.006 & -0.224 & 0.107 & -2.090 & 0.036 \\
\hline Liquidity constraints: no & 0.208 & 0.098 & 2.110 & 0.035 & 0.129 & 0.103 & 1.250 & 0.212 & 0.176 & 0.089 & 1.970 & 0.048 & 0.347 & 0.101 & 3.450 & 0.001 & 0.359 & 0.113 & 3.190 & 0.001 \\
\hline Inventories above normal & 0.337 & 0.141 & 2.390 & 0.017 & 0.047 & 0.155 & 0.300 & 0.761 & 0.196 & 0.143 & 1.370 & 0.171 & 0.303 & 0.119 & 2.550 & 0.011 & 0.064 & 0.153 & 0.420 & 0.677 \\
\hline$(\operatorname{lnv} / E m p l)_{t-1}$ & 0.311 & 0.042 & 7.360 & 0.000 & 0.394 & 0.041 & 9.670 & 0.000 & 0.250 & 0.033 & 7.630 & 0.000 & 0.230 & 0.030 & 7.690 & 0.000 & 0.255 & 0.041 & 6.200 & 0.000 \\
\hline c & -0.754 & 0.083 & -9.120 & 0.000 & -0.918 & 0.088 & -10.400 & 0.000 & -0.907 & 0.090 & -10.120 & 0.000 & -1.268 & 0.084 & -15.120 & 0.000 & -1.255 & 0.090 & -13.960 & 0.000 \\
\hline \multicolumn{21}{|l|}{ Permanent Hirings } \\
\hline Innovative Investments & 0.758 & 0.272 & 2.780 & 0.005 & 0.363 & 0.197 & 1.840 & 0.066 & 0.521 & 0.237 & 2.200 & 0.028 & 0.498 & 0.653 & 0.760 & 0.446 & 0.222 & 0.273 & 0.810 & 0.417 \\
\hline Demand: high & 0.210 & 0.122 & 1.720 & 0.086 & 0.063 & 0.120 & 0.530 & 0.597 & 0.255 & 0.126 & 2.030 & 0.042 & 0.338 & 0.175 & 1.930 & 0.053 & 0.254 & 0.151 & 1.680 & 0.093 \\
\hline Increase Labour cost> 3\% & -0.002 & 0.141 & -0.010 & 0.990 & 0.038 & 0.122 & 0.310 & 0.754 & 0.011 & 0.129 & 0.090 & 0.932 & 0.170 & 0.113 & 1.510 & 0.130 & 0.153 & 0.127 & 1.200 & 0.231 \\
\hline Liquidity constraints: yes & 0.045 & 0.146 & 0.310 & 0.758 & -0.282 & 0.139 & -2.030 & 0.042 & -0.312 & 0.120 & -2.590 & 0.010 & -0.094 & 0.102 & -0.920 & 0.358 & -0.236 & 0.113 & -2.090 & 0.036 \\
\hline c & -1.175 & 0.083 & -14.150 & 0.000 & -1.066 & 0.074 & -14.340 & 0.000 & -1.056 & 0.066 & -15.980 & 0.000 & -1.421 & 0.084 & -16.890 & 0.000 & -1.278 & 0.079 & -16.200 & 0.000 \\
\hline \multicolumn{21}{|l|}{ Substitution Investment } \\
\hline $\begin{array}{l}\text { Permanent Hirings } \\
\text { Pent }\end{array}$ & 0.774 & 0.898 & 0.860 & 0.389 & 1.404 & 0.226 & 6.200 & 0.000 & 1.350 & 0.513 & 2.630 & 0.008 & 0.786 & 0.527 & 1.490 & 0.135 & 1.207 & 0.309 & 3.910 & 0.000 \\
\hline Innovative Investments & 0.538 & 0.311 & 1.730 & 0.084 & 1.086 & 0.231 & 4.710 & 0.000 & 0.713 & 0.392 & 1.820 & 0.069 & 0.644 & 0.299 & 2.150 & 0.031 & 0.592 & 0.235 & 2.520 & 0.012 \\
\hline Increase Labour cost> $3 \%$ & 0.293 & 0.136 & 2.160 & 0.031 & 0.198 & 0.094 & 2.100 & 0.036 & 0.169 & 0.107 & 1.590 & 0.113 & -0.021 & 0.092 & -0.220 & 0.823 & 0.038 & 0.126 & 0.300 & 0.763 \\
\hline c & -0.431 & 0.118 & -3.660 & 0.000 & -0.739 & 0.055 & -13.500 & 0.000 & -0.469 & 0.065 & -7.190 & 0.000 & -0.467 & 0.060 & -7.760 & 0.000 & -0.584 & 0.051 & -11.430 & 0.000 \\
\hline \multicolumn{21}{|l|}{ Flexible hirings } \\
\hline Substitution Investment & -0.046 & 0.730 & -0.060 & 0.950 & 0.676 & 0.459 & 1.470 & 0.141 & -0.429 & 0.370 & -1.160 & 0.245 & -0.503 & 1.222 & -0.410 & 0.681 & -0.831 & 0.409 & -2.030 & 0.042 \\
\hline Permanent Hirings & 0.461 & 0.979 & 0.470 & 0.638 & -0.684 & 0.795 & -0.860 & 0.389 & 0.979 & 0.588 & 1.660 & 0.096 & 1.039 & 0.932 & 1.110 & 0.265 & 0.158 & 0.556 & 0.280 & 0.777 \\
\hline Innovative Investments & 0.463 & 0.395 & 1.170 & 0.241 & 0.597 & 0.365 & 1.640 & 0.102 & 0.956 & 0.314 & 3.050 & 0.002 & 0.874 & 0.278 & 3.150 & 0.002 & 0.624 & 0.288 & 2.170 & 0.030 \\
\hline Liquidity constraints: yes & -0.223 & 0.128 & -1.740 & 0.082 & -0.267 & 0.160 & -1.680 & 0.094 & -0.074 & 0.129 & -0.580 & 0.565 & -0.064 & 0.091 & -0.700 & 0.487 & -0.065 & 0.088 & -0.740 & 0.456 \\
\hline Inventories below normal & 0.264 & 0.160 & 1.660 & 0.098 & -0.048 & 0.154 & -0.320 & 0.753 & 0.147 & 0.139 & 1.060 & 0.290 & 0.128 & 0.126 & 1.020 & 0.307 & -0.100 & 0.155 & -0.650 & 0.518 \\
\hline Increase Labour cost> 3\% & 0.234 & 0.156 & 1.500 & 0.135 & -0.058 & 0.132 & -0.440 & 0.660 & 0.028 & 0.112 & 0.250 & 0.804 & -0.036 & 0.103 & -0.350 & 0.724 & 0.199 & 0.138 & 1.440 & 0.149 \\
\hline c & -1.082 & 0.285 & -3.790 & 0.000 & -1.256 & 0.175 & -7.170 & 0.000 & -1.023 & 0.199 & -5.150 & 0.000 & -1.113 & 0.750 & -1.480 & 0.138 & -0.610 & 0.310 & -1.970 & 0.049 \\
\hline /atanhrho_12 & -0.298 & 0.193 & -1.550 & 0.122 & 0.041 & 0.123 & 0.340 & 0.736 & -0.094 & 0.123 & -0.760 & 0.444 & -0.145 & 0.372 & -0.390 & 0.697 & 0.128 & 0.159 & 0.800 & 0.421 \\
\hline /atanhrho 13 & -0.041 & 0.168 & -0.250 & 0.806 & -0.617 & 0.196 & -3.140 & 0.002 & -0.491 & 0.275 & -1.790 & 0.074 & -0.278 & 0.183 & -1.520 & 0.129 & -0.283 & 0.152 & -1.870 & 0.062 \\
\hline /atanhrho_14 & -0.140 & 0.218 & -0.640 & 0.520 & -0.205 & 0.216 & -0.950 & 0.343 & -0.425 & 0.204 & -2.080 & 0.037 & -0.277 & 0.185 & -1.500 & 0.135 & -0.153 & 0.162 & -0.940 & 0.348 \\
\hline /atanhrho_23 & -0.371 & 0.577 & -0.640 & 0.520 & -0.932 & 0.290 & -3.210 & 0.001 & -0.633 & 0.494 & -1.280 & 0.200 & -0.273 & 0.268 & -1.020 & 0.308 & -0.559 & 0.207 & $\begin{array}{l}-2.690 \\
\end{array}$ & 0.007 \\
\hline /atanhrho_24 & -0.095 & 0.540 & -0.180 & 0.860 & 0.365 & 0.491 & 0.740 & 0.457 & -0.420 & 0.349 & -1.200 & 0.229 & -0.532 & 0.478 & -1.110 & 0.266 & 0.145 & 0.324 & 0.450 & 0.654 \\
\hline /atanhrho_34 & 0.167 & 0.489 & 0.340 & 0.733 & -0.258 & 0.435 & -0.590 & 0.553 & 0.491 & 0.289 & 1.700 & 0.089 & 0.550 & 0.980 & 0.560 & 0.575 & 0.819 & 0.384 & 2.130 & 0.033 \\
\hline$\rho_{1,2}$ & -0.289 & 0.177 & & & 0.041 & 0.123 & & & -0.094 & 0.122 & & & -0.144 & 0.365 & & & 0.128 & 0.157 & & \\
\hline$\rho_{1,3}$ & -0.041 & 0.168 & & & -0.549 & 0.137 & & & -0.455 & 0.218 & & & -0.271 & 0.170 & & & -0.276 & 0.140 & & \\
\hline$\rho_{1,4}$ & -0.139 & 0.214 & & & -0.202 & 0.207 & & & -0.401 & 0.171 & & & -0.270 & 0.172 & & & -0.151 & 0.159 & & \\
\hline$\rho_{2,3}$ & -0.355 & 0.504 & & & -0.731 & 0.135 & & & -0.560 & 0.339 & & & -0.267 & 0.249 & & & -0.507 & 0.154 & & \\
\hline$\rho_{2,4}$ & -0.095 & 0.535 & & & 0.350 & 0.431 & & & -0.397 & 0.294 & & & -0.487 & 0.365 & & & 0.144 & 0.317 & & \\
\hline$\rho_{3,4}$ & 0.165 & 0.476 & & & -0.253 & 0.408 & & & 0.455 & 0.229 & & & 0.500 & 0.734 & & & 0.674 & 0.209 & & \\
\hline $\begin{array}{l}\text { Log pseudolikelihood } \\
\text { Number of obs } \\
\text { Wald chi2(4) } \\
\text { Prob > chi2 }\end{array}$ & $\begin{array}{r}-1036246.100 \\
2260 \\
75.910 \\
0.000\end{array}$ & & & & $\begin{array}{r}-914985.130 \\
2104 \\
106.120 \\
0.000\end{array}$ & & & & $\begin{array}{r}-890198.850 \\
2383 \\
118.180 \\
0.000\end{array}$ & & & & $\begin{array}{r}-780219.400 \\
3147 \\
97.360 \\
0.000\end{array}$ & & & & $\begin{array}{r}-726688.840 \\
3103 \\
56.940 \\
0.000\end{array}$ & & & \\
\hline
\end{tabular}


DEPARTMENT OF ECONOMICS AND PUBLIC FINANCE "G. PRATO" UNIVERSITY OF TORINO

Corso Unione Sovietica 218 bis - 10134 Torino (ITALY)

Phone: +390116706128 - Fax: +390116706062

Web page: http://eco83.econ.unito.it/prato/ 